\title{
Analysis of Construction Impact of A Large Diameter Shield Tunnelling Side-Crossing Viaduct Pile Foundations in Short Distance
}

\author{
Jian Wang ( $\nabla$ wangjian85941420@163.com ) \\ Hunan City University \\ Zhifang Wen \\ Hunan City University Design And Reasearch Institute Co., Ltd
}

\section{Research Article}

Keywords: Large diameter shield, Viaduct pile foundations, Shield side-crossing, Numerical simulation

Posted Date: February 23rd, 2021

DOl: https://doi.org/10.21203/rs.3.rs-223623/v1

License: @ (i) This work is licensed under a Creative Commons Attribution 4.0 International License. Read Full License 


\section{Abstract}

The construction of shield tunneling through pile foundation will cause additional deformation and internal force of pile foundation, which will affect the safety and applicability of superstructure. Based on the engineering background of a large-diameter shield (\$10.9 m) side crossing a viaduct, a three-dimensional finite element model for the construction of large-diameter shield side crossing viaduct pile foundations is established by using the finite element method. The reliability of the numerical model is verified by using the surface subsidence calculated by Peck formula as a reference. Based on this, the viaduct pier and piles additional response during the construction are developed, the analysis results shows that: Because the pile foot of the viaduct is located below the tunnel, the pier deformation during the shield construction is mainly in the transverse direction along the bridge; The deformation of piles is mainly lateral and vertical, and the lateral deformation is S-shaped, the deformation of piles near the tunnel axis is far away from the tunnel side, and the piles at this position has the maximum lateral deformation; The variation characteristics of the additional internal force of piles are similar to the additional deformation, the position of the maximum additional bending moment is consistent with the position of the maximum lateral deformation, while the maximum additional shear force of pile foundation is slightly lower than the tunnel axis. And the protection measures of elevated pile foundation proposed by the project are demonstrated, The calculation results show that the additional deformation of pier and piles has been significantly improved after taking the measures of stratum reinforcement, and its value is far lower than the standard control value.

\section{Introduction}

In the current urban subway construction in various countries, shield construction method has become the preferred method for constructing subways in many cities due to its advantages, such as high degree of mechanization, small impacts on the environment, safe and efficiency. In recent years, with the continuous improvement of equipment and construction technologies, an increasing number of large-diameter shield tunnels are emerging, such as Daejeon subway line 2 in Korea ( $\$ 11.35 \mathrm{~m})$, Beijing subway line 14 in China ( $\$ 10.22 \mathrm{~m}$ ), Nanjing Weisan Road river-crossing tunnel (\$14.93 m) in China· (Xu et al. 2020; Mashimo and Ishimura. 2003; Cheng et al. 2019; Zhang et al. 2020). In urban tunnel construction, due to the shortage of underground room, construction of shield tunnels passing by underground structures keeps emerging. Particularly, the construction using a shield machine side-crossing and under-crossing pile foundations of existing buildings or structures is most commonly seen. However, these nodes where the shield machine passes by pile foundations generally become the risk control points during shield construction. Therefore, studying additional response of the adjacent pile foundations to shield construction passing by is of practical significance.

In essence, the response of pile foundations caused by shield construction is a topic relating to passive piles. In other words, deformation of surrounding strata caused by shield construction renders the strata bearing pile foundations to additional load, thus leading to additional deformation and additional internal forces. Scholars in China and abroad have conducted a lot of researches on additional response of the adjacent pile foundations to shield construction and obtained some results (Kaalberg et al. 2005; Sirivachiraporn and Phienwej. 2012; Xu et al. 2015; Teparaksa et al. 2006; Li et al. 2020). However, the current studies mainly focus on the construction of subways passing by buildings using a conventional shield machine, while the 
construction using a large-diameter shield machine passing by pile foundations is rarely researched. At present, the methods for studying this topic mainly include theoretical analysis, numerical simulation, model test and field test. Among these research methods, by virtue of large finite element software, numerical simulation can be used to establish an overall analysis model for shield-soil-pile foundations, which can fully consider the interaction between piles and soil and dynamic construction process of the shield machine. Therefore, this method is very popular (Nematollahi and Dias. 2019; Lv et al. 2020).

As the shield machine further develops to have a larger diameter, it is more difficult to control its postures and cutter. In the construction using the large-diameter shield machine side-crossing pile foundations, additional response of pile foundations is easily caused, which affects applicability and safety of superstructure. Therefore, studying the construction with the large-diameter shield machine crossing through pile foundations and exploring the characteristics of additional response of pile foundations has certain guiding significance to the safe shield construction. Against the background of a large-diameter subway tunnel side-crossing pile foundations of an overpass, three-dimensional (3D) numerical simulation was performed on construction with the shield machine side-crossing through pile foundations by using the finite element method. Moreover, this study investigated response characteristics of bridge piers and pile foundations in the lower part of the overpass to the construction using the large-diameter shield machine side-crossing pile foundations, so as to provide guidance for the safe shield construction at site.

\section{Project Profile}

A subway tunnel designed with double lanes in a single hole was constructed with a large-diameter $(10.9 \mathrm{~m})$ earth-pressure balance shield by using shield tunneling method. The universal wedge-shaped segments were used as lining in the interval tunnel and a ring of lining comprised one block for roofing ( $F x)$, two adjacent blocks ( $L x)$ and five standard blocks (Bx). Segmental lining with an outer diameter of $10.5 \mathrm{~m}$, a thickness of $0.5 \mathrm{~m}$ showed ring width of $2 \mathrm{~m}$ and C50 high-strength concrete was used for the lining segments. For the tunnel line, the maximum longitudinal slope was $27 \%$ and the minimum radius of horizontal curve was $R=$ $450 \mathrm{~m}$. The top of the tunnel was covered by a soil layer with thickness of 11.4 26.8 m. During the tunnel construction at the DK18+182, the shield machine laterally passed by the pile foundations of the overpass and the outside of the tunnel was only $7.38 \mathrm{~m}$ away from the nearest bridge pile, as shown in Fig. 1. The cushion cap of the overpass was buried at about $0.4 \mathrm{~m}$ and had dimensions of $6.0 \mathrm{~m} \times 6.0 \mathrm{~m} \times 2.0 \mathrm{~m}$. The piles lay on friction foundations with the length of $40 \mathrm{~m}$ and diameter of $1.25 \mathrm{~m}$. The bridge piers, cushion cap and bridge piles were built using $\mathrm{C} 30$ concrete.

Strata in the section where the shield machine side-crossing the bridge piles composed of miscellaneous fill, mud clay, sandy silt, silty clay, mixed layer of silty clay and fine silt and fine sand from the top to bottom. The layer of silty clay and the layer mixing silty clay and fine silt were observed in the strata passed by the shield machine. Highly weathered argillaceous siltstone was found in underlying bedrock at site. Based on investigation data of geotechnical engineering, groundwater was developed at site and its level stabilized at about $2 \mathrm{~m}$ underground. The transverse section of shield construction side-crossing pile foundations is shown in Fig. 1. 


\section{Numerical Simulation Of A Large-diameter Shield Machine Side- crossing The Bridge Pile Foundations}

\subsection{Model overview}

The aim of this study is to analyze response of the overpass to tunnel construction using a large-diameter shield machine side-crossing pile foundations, especially the effects on pile foundations of the overpass. For this purpose, the overall 3D finite element model for construction using the large-diameter shield machine sidecrossing the pile foundations was built by utilizing the universal finite element software ABAQUS. By considering boundary effects and calculation efficiency, the numerical model showed dimensions of $120 \mathrm{~m} \times$ $50 \mathrm{~m} \times 80 \mathrm{~m}$. The buried depth of the tunnel axis was $24 \mathrm{~m}$, and the radius of excavation by the shield machine was $5.45 \mathrm{~m}$. Moreover, the shield machine tunneled along the $Y$ direction. The displacement boundary was used in the model, which separately constrained normal displacement of the sides and the bottom of the model. The established numerical model is shown in Fig. 2.

\subsection{Contact relationship of parameters in model calculation}

In analysis, the equivalent circle zone is used to comprehensively reflect shield tail gaps, filling of soil into shield tail gaps, distribution of slurry after grouting, and the disturbance degree and scope of the surrounding rock around the hole during shield construction (Chen et al. 2010). The thickness of the equivalent circle zone is determined by the following formula.

$$
\delta=\eta \Delta
$$

where, $\delta$ and $\Delta$ represent the thickness of the equivalent circle zone and theoretical value of shield tail gaps, respectively; $\eta$ indicates the reduction factor and values in the range of $0.7 \sim 2.0$.

In the calculation, considering engineering characteristics of shield tunneling crossing strata, $\eta=1.0$, so the thickness of the equivalent circle zone is calculated as $\delta=0.4 \mathrm{~m}$.

In the model, except for shield shell which was simulated with a shell element (S4R), other parts were simulated by solid elements (C3D8R). The ideal elasto-plastic constitutive relationship was used for soil. Owing to the parameters of Mohr-Coulomb model were easily determined and sand layer was dominant strata at site, Mohr-Coulomb criterion was used as the yield criterion of soil. The physico-mechanical parameters of strata in the model were determined according to the survey report of geotechnical engineering and the soil parameters used in the calculation are listed in Table 1. Linear elastic constitutive relationship was employed for analyzing the shield shell, lining, equivalent circle zone and bridge structure. By changing elastic modulus of the equivalent circle zone, the behavior of the grouting slurry during shield construction was changed in the model. The values were used for the elastic moduli of the equivalent circle zone in the early and later stages (Liu et al. 2014). Physico-mechanical parameters of the structure in the model are listed in Table 2.

\section{Table 1 Physico-mechanical parameters of soil}




\begin{tabular}{|c|c|c|c|c|c|c|c|}
\hline Strata & $\begin{array}{l}\text { Thickness } \\
/(h / \mathrm{m})\end{array}$ & $\begin{array}{l}\text { Weight } \\
/\left(y / \mathrm{kN} \cdot \mathrm{m}^{-3}\right)\end{array}$ & $\begin{array}{l}\text { Elastic } \\
\text { modulus } \\
/\left(E_{s} / \mathrm{MPa}\right)\end{array}$ & $\begin{array}{l}\text { Poisson's } \\
\text { ratio } \\
/(\mu)\end{array}$ & $\begin{array}{l}\text { Cohesion } \\
/(c / \mathrm{kPa})\end{array}$ & 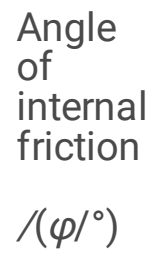 & $\begin{array}{l}\text { Lateral } \\
\text { pressure } \\
\text { coefficient } \\
/\left(K_{0}\right)\end{array}$ \\
\hline $\begin{array}{l}\text { Miscellaneous } \\
\text { fill }\end{array}$ & 0.8 & 18.0 & 10 & 0.36 & 8 & 10 & 0.56 \\
\hline Mud clay & 5.2 & 17.4 & 8 & 0.38 & 10 & 8 & 0.61 \\
\hline Sandy silt & 9.0 & 18.2 & 40 & 0.3 & 2 & 26 & 0.43 \\
\hline Silty clay & 9.0 & 18.1 & 22 & 0.34 & 18 & 12 & 0.52 \\
\hline $\begin{array}{l}\text { Layer mixing } \\
\text { silty clay and } \\
\text { fine sand }\end{array}$ & 16.0 & 18.4 & 20 & 0.35 & 16 & 15 & 0.54 \\
\hline Fine sand & 20.0 & 19.5 & 60 & 0.28 & 8 & 32 & 0.39 \\
\hline $\begin{array}{l}\text { Highly } \\
\text { weathered } \\
\text { argillaceous } \\
\text { sandstone }\end{array}$ & 20.0 & 24.3 & 200 & 0.24 & 8018.2 & 35 & 0.32 \\
\hline
\end{tabular}

Table 2 Parameters of the equivalent circle zone and other structures and materials

\begin{tabular}{|lllll|}
\hline Part & Material & $\begin{array}{l}\text { Weight } \\
\left(\gamma / \mathrm{kN} \cdot \mathrm{m}^{-3}\right)\end{array}$ & $\begin{array}{l}\text { Elastic modulus } \\
/(E / \mathrm{MPa})\end{array}$ & $\begin{array}{l}\text { Poisson's ratio } \\
/(\mu)\end{array}$ \\
\hline Bridge beam & C30 concrete & 25 & $2.88 \times 10^{4}$ & 0.2 \\
\hline Lining segment & C50 concrete & 25 & $3.45 \times 10^{4}$ & 0.2 \\
\hline Shield & Steel & 78.5 & $2.10 \times 10^{5}$ & 0.3 \\
Equivalent Circle Zone & - & 20 & 2.4 (Early stage) & 0.35 (Early stage) \\
& & & 150 (Later stage) & 0.3 (Later stage) \\
\hline
\end{tabular}

In order to better simulate interaction between bridge piles and soil, the classical Coulomb frictional contact was used for the cushion cap and bridge piles with soil to establish the contact relationship between the structure and soil. Hard contact was used in normal direction between two contact surfaces and penalty function was utilized to describe the frictional contact relationship in tangential direction. The frictional angle at the interface between piles and soil was the one at the interface between concrete and soil, namely $\theta=2 \varphi / 3$ (Boldini et al. 2018). In the calculation, $\varphi$ valued the weighted average of the angle of internal friction of soil in the depth range of the cushion cap and piles.

\subsection{Simulation of shield construction}


The finite element simulation of shield construction was essentially to simulate the migration of stiffness and load of the shield machine in the model and the stiffness of the elements was changed based on the method of activating and deactivating elements. As the excavation face advanced, the shield shell gradually penetrated the strata and the shield tail gradually came out. Moreover, lining element was activated to bear the pressures of surrounding water and soil. The simulation of dynamic shield construction in the model is shown in Fig. 3. In the model, 6 rings tunneled by the shield machine were regarded as a working cycle. When the shield machine tunneled to the seventh ring, the first ring of shield tunneling was deactivated, while the first ring of lining and the equivalent circle zone were activated. In the meanwhile, the grouting pressure was applied on the outer wall of the lining and the inner wall of surrounding rock around the hole. As the shield machines tunneled to the eighth ring, the second ring tunneled with the shield machine was deactivated, while the second ring of lining and the equivalent circle zone were activated. Moreover, grouting pressure was performed on the corresponding position. By considering hardening of the slurry, elastic modulus of the equivalent circle zone was changed by a temperature field. The subsequent construction steps could be repeated according to this cycle. In addition, to consider the disturbance and damages of shield cutter to the surrounding rock ahead, a temperature field was used to soften the surrounding rock ahead of excavation face, and then reduce elastic modulus of the softened soil to $60 \%$ of the original one in the model. The non-uniform distribution mode was used in distribution model of backfill grouting pressures of shield tail. According to the existing engineering experience, the backfill grouting pressure was $0.2 \mathrm{MPa}$ at the top and $0.3 \mathrm{MPa}$ at the bottom of the tunnel.

\subsection{Model verification}

Ground loss during shield tunneling could result in displacement of surrounding soil. Many scholars in the world have studied this problem and proposed a series of prediction methods for stratum deformation in shield construction, of which Peck's formula established based on Gaussian distribution function was most widely used (Peck. 1969). This study verified the reliability of the numerical model by comparing the consistency of transverse surface subsidence curves caused by shield construction obtained by using Peck's formula and the numerical model established. Fig. 4 shows transverse surface subsidence curves after shield tunneling obtained by the model and calculated by Peck's formula. Transverse surface subsidence in the numerical model valued data at measuring lines in Fig. 2. In the calculation with Peck's formula, width factor of a subsider and ground loss rate were $k=0.6$ and $\eta=1.0 \%$ by taking strata conditions at engineering site into consideration (Peck. 1969; Attewell. 1982).

As demonstrated in Fig. 4, surface subsidence curve caused by shield construction obtained by using the numerical model in this study can well coincide with that obtained by utilizing Peck's empirical formula, indicating that the numerical model in this study is reliable to some extent and the calibrated parameters are accurate. Therefore, the numerical model can be used to further analyze response of the adjacent bridge piles to shield construction.

\section{Analysis Of Calculation Results}

During construction with the shield machine side-crossing pile foundations, the response of the adjacent bridge structure is a process of 3D dynamic change. With the excavation face moving forward, the bridge 
response constantly changes.

In some existing standards and specifications, the control value of deformation of bridge piers is stipulated. The requirements for allowable deformation of bridge foundation are not clearly specified. For this reason, the relevant provisions are taken as the standards for controlling deformation of bridge piers and foundation of the overpass during project construction using the shield machine passing by the pile foundations in this analysis, shown as follows,

(1) The uneven subsidence between the adjacent piers should not cause an additional longitudinal slope of the bridge deck greater than $0.2 \%$, so the limit of uneven subsidence between two bridge piers in this project is $\Delta U_{z}$ $=70 \mathrm{~mm}$.

(2) The horizontal displacement on the top of piers along the overpass should meet the following formula.

$$
\Delta U_{x} \leq 5 \sqrt{L_{0}}
$$

where, $L_{0}$ indicates the bridge span and its value can refer to relevant specifications. Through calculation, the limit of horizontal displacement on the top of piers along the overpass is $\Delta U_{X}=29.6 \mathrm{~mm}$ in this project.

(3) The allowable horizontal displacement of pile foundations on the ground is $10 \mathrm{~mm}$, while it is $6 \mathrm{~mm}$ for the buildings that are sensitive to horizontal displacement.

\subsection{Analysis on deformation of bridge piers}

\subsubsection{Analysis on vertical deformation of bridge piers}

During shield tunneling, the change curve of vertical displacement of the adjacent bridge piers of the overpass is displayed in Fig. 5. As shown in the figure, due to difference of distances from the tunnel, the changes of vertical displacement on the top of two bridge piers are largely different and such a difference mainly appears in the range of $20 \sim 40 \mathrm{~m}$ of excavation length. Within this range, differential subsidence on the top of the two bridge piers obviously increases. As the excavation length of shield tunneling exceeds $40 \mathrm{~m}$, differential subsidence on the top of the piers gradually tends to be stable. Based on calculation, the maximum differential subsidence on the top of the piers is only $0.68 \mathrm{~mm}$ during shield construction, which is much smaller than the specified value in the above specifications. Obviously, for this project, attributed to the long pile foundations of the overpass, differential subsidence of the bridge piers of the overpass caused by shield construction is unobvious. Furthermore, it is worth noting that a large difference in subsidence on the top of the two bridge piers is present before and after excavation length reaches $20 \mathrm{~m}$. To be specific, within excavation length of 12 20 $\mathrm{m}$, as the excavation face constantly moves forward, soil in front of the cutter is disturbed, so that subsidence on the top of the piers gradually rebounds. When excavation length is $22 \mathrm{~m}$, the excavation face is in the range of bridge piers. In this case, the surrounding rock at the bottom of the tunnel is upheaved as a result of tunnel excavation, leading to rebound of the bridge piers from vertical displacement. Particularly, for QD-1, owing to the end of piles is located within the upheaval range of surrounding rock at the bottom of the tunnel, as shown in Fig. 6, the rebound is greater. As the shield machine advances, the excavation area 
gradually expands and rebound of bridge piers gradually increases till the shield tail depart completely from the range of bridge piers, namely excavation length $L=38 \mathrm{~m}$.

\subsubsection{Analysis on transverse deformation of bridge piers}

Figure 7 demonstrates change curve of horizontal displacement of the bridge piers along the overpass with excavation length with the shield machine. It can be seen from the figure that compared with vertical deformation, transverse deformation of bridge piers caused by shield tunneling side-crossing pile foundations is more obvious. Transverse deformation on the top of the two bridge piers is shown as deviation to the tunnel, while vertical deformation of the same bridge piers develops in a similar trend. Transverse deformation of the bridge piers shows obvious stages and each development stage basically is a cycle of shield excavation. Owing to QD-1 is closer to the tunnel than QD-2, the influences of shield construction on QD-1 are greater. When excavation length with the shield machine is $L=50 \mathrm{~m}$, transverse displacements on the top of the two bridge piers reach the maximum and are $10.71 \mathrm{~mm}$ and $-9.16 \mathrm{~mm}$, respectively. The relative horizontal displacement of bridge piers along the overpass is $19.87 \mathrm{~mm}$, which is slightly smaller than the control value of $29.6 \mathrm{~mm}$ stipulated in the aforementioned specifications.

In the monitoring of field construction, $70 \%$ of the standard reference value is usually used for early warning for construction. On this basis, the early warning value of relative horizontal displacement of the adjacent bridge piers along the overpass in the shield construction crossing the pile foundations is $20.72 \mathrm{~mm}$. It is obvious that the horizontal displacement of bridge piers easily reaches the early warning value during shield construction. Therefore, certain measures for protecting pile foundations of the overpass are required in the construction and shield tunneling parameters should be controlled reasonably at the same time.

\subsection{Analysis on deformation of pile foundations}

Table 3 lists the maximum transverse and vertical displacements of each pile foundation after shield construction. It can be seen from the table that deformation of pile foundations caused by shield construction is mainly dominated by the transverse deformation along the overpass and vertical subsidence. Of them, the maximum transverse deformation of pile foundations is located at the tunnel axis and characterized by deviation away from the tunnel. The maximum subsidence of pile foundations is mainly found on the upper part of pile foundations, which mainly results from subsidence on the top of piles induced by transverse bending and deformation of pile foundations. In addition, as illustrated in Table 3, due to the isolation effect of pile foundations in the front row, deformation of pile foundations in the rear row is obviously small.

\section{Table 3 The maximum deformation of pile foundations after shield construction ( $\mathrm{mm}$ )}




\begin{tabular}{|lllll|}
\hline Bridge pier & Pile & $U_{x, \max }$ & $U_{y, \max }$ & $U_{z, \max }$ \\
\hline QD-1 & QZ1-1 & -9.74 & +2.68 & -5.59 \\
\cline { 2 - 5 } & QZ1-2 & -9.98 & +1.35 & -5.12 \\
& QZ1-3 & -8.04 & +1.93 & -4.35 \\
\cline { 2 - 5 } & QZ1-4 & -8.15 & +0.93 & -3.91 \\
& QZ2-1 & +8.89 & +1.91 & -5.85 \\
& QZ2-2 & +9.08 & +1.07 & -5.53 \\
& QZ2-3 & +7.30 & +1.36 & -4.31 \\
\hline & QZ2-4 & +7.37 & +0.70 & -4.00 \\
\hline
\end{tabular}

Because deformation of foundations under each bridge pier is similar, characteristics of transverse deformation of pile foundations on both sides of the tunnel during shield tunneling were analyzed by taking QZ1-1 and QZ2-1 as examples. Figs. 8 and 9 demonstrate transverse deformation curves of QZ1-1 and QZ2-1 when the excavation face lies in different positions. Owing to the length of six rings of segments is used as an excavation cycle in the calculation model, the lengths of the excavation face are $L=10 \mathrm{~m}, 22 \mathrm{~m}, 34 \mathrm{~m}$ and 46 $\mathrm{m}$.

As illustrated in Figs. 8 and 9, deformation characteristics of pile foundations of the overpass on both sides of the tunnel are similar during the shield tunneling, showing obvious S-shaped transverse bending and deformation. Near the tunnel axis, pile foundations on both sides present lateral deflection far away from the tunnel. The top and end of a pile deviate to the tunnel and the closer the pile foundation to the tunnel, the more obvious the effects of shield construction on the end of the pile foundation. When the excavation face is located at $10 \mathrm{~m}$ in front of the pile $(L=10 \mathrm{~m})$, transverse deformation of the pile foundation is small. As the excavation face passes by the pile foundation $(L=22 \mathrm{~m})$, transverse deformation of the pile foundation gradually increases but does not develop rapidly due to protection of shield shell. When shield tail departs the pile foundation $(L=34 \mathrm{~m}$ ), deformation of the pile foundation obviously rises. With further shield tunneling, transverse deformation of the pile foundation reaches the peak in the later stage of consolidation and settlement of surrounding rock.

By taking the selected working conditions for analysis as an example, when excavation length is $L=46 \mathrm{~m}$, horizontal displacements on the top of QZ1-1 and QZ2-1 piles are $4.3 \mathrm{~mm}$ and $4.1 \mathrm{~mm}$, respectively. Because the pile foundations of the overpass are structures sensitive to horizontal displacement, horizontal displacement of pile foundations caused by shield construction is slightly smaller than the control value in the above specifications but larger than the early warning value for construction.

Figure 10 shows transverse deformation curves of QZ1-1 and QZ1-3 under excavation lengths of $L=22 \mathrm{~m}, 34$ $\mathrm{m}$ and $46 \mathrm{~m}$. It can be observed from the figure that transverse deformation of the pile foundations on the same side is consistent during shield construction. However, due to isolation effect of pile foundations in the front row, response of the pile foundations in the rear row to shield construction obviously reduces. 


\subsection{Analysis on internal force of pile foundations}

Transverse shear forces and bending moments of QZ1-1 and QZ1-3 when the excavation face is located at different positions are shown in Figs. 11 and 12. As demonstrated in the figures, owing to QZ1-1 is closer to the tunnel than QZ2-1, additional internal force of QZ1-1 induced by shield construction is larger. On the whole, the changes of additional internal force of pile foundations in the transverse direction are consistent with transverse deformation. However, it should be noted that compared with additional deformation of the pile foundation caused by shield construction, the additional internal force induced by shield tunneling increases slowly when the excavation face is ahead of the pile foundation. As shield tail at the pile foundation departs from the pile foundation $(L=34 \mathrm{~m}$ ), additional internal force of the pile foundation obviously rises.

Furthermore, in terms of the positions where the maximum shear force and bending moment appear, the maximum additional bending moment and the maximum transverse deformation of the pile foundation are found at the same position, slightly above the tunnel axis, while the maximum additional shear force is located below the tunnel axis.

Based on the selected working conditions for analysis in this section, when excavation length is $L=46 \mathrm{~m}$, additional internal forces of QZ1-1 and QZ1-2 reach the maximum. The maximum shear forces are $141.3 \mathrm{kN}$ and $65.5 \mathrm{kN}$, and the maximum bending moments are $422.3 \mathrm{kN} \cdot \mathrm{m}$ and $276.9 \mathrm{kN} \cdot \mathrm{m}$, respectively.

\section{Analysis On Protection Measures For Bridge Piles}

In accordance with previous analysis on deformation of bridge piers and pile foundations, horizontal displacements of bridge piers along the overpass and of pile foundations easily reach the control value stipulated in the specification during the shield tunneling side-crossing the overpass. Therefore, in order to ensure safety of the overpass and reduce risks during shield construction, certain protection measures need to be taken. The shield tunneling line has a certain distance from the bridge pile, so the protection measure of enhancing strata around the hole by grouting was taken. According to the design requirements of the project, the range of reinforcement along the longitudinal direction of the tunnel is about three times the width of the cushion cap beneath the bridge piers, namely $18 \mathrm{~m}$, and the reinforcement range on transverse section is about $31.3 \mathrm{~m} \times 20.5 \mathrm{~m}$. The transverse section with the strata reinforced by grouting is shown in Fig. 13 .

Table 4 lists the calculated values of key indexes of bridge piers and pile foundations after the shield construction side-crossing the overpass before and after reinforcing strata by grouting. As shown in the table, after reinforcing strata, deformations of bridge piers and pile foundations obviously reduce. After shield construction, relative horizontal displacement of bridge piers is only $6.35 \mathrm{~mm}$ and horizontal displacement on the top of the piles is only $4.94 \mathrm{~mm}$. The above values are much smaller than the control values stipulated in the specifications and early warning values for construction, indicating that good control effects on the construction can be obtained by foundation treatment before the shield machine passing by the overpass.

Table 4 Comparison of key indexes of bridge piers and pile foundations of the overpass before and after strata reinforcement 


\begin{tabular}{|c|c|c|c|}
\hline Index & $\begin{array}{l}\text { Before } \\
\text { grouting }\end{array}$ & $\begin{array}{l}\text { After } \\
\text { grouting }\end{array}$ & $\begin{array}{l}\text { Change } \\
\text { amplitude }\end{array}$ \\
\hline $\begin{array}{l}\text { Relative horizontal displacement of bridge piers } /\left(\Delta U_{x} /\right. \\
\mathrm{mm})\end{array}$ & 19.87 & 6.35 & $68.04 \%(\downarrow)$ \\
\hline Horizontal displacement on the top of piles/( $\left.U_{x} / \mathrm{mm}\right)$ & 4.32 & 0.94 & $78.24 \%(\downarrow)$ \\
\hline $\begin{array}{l}\text { Maximum transverse deformation of bridge } \\
\text { piles } /\left(U_{x, \max } / \mathrm{mm}\right)\end{array}$ & 9.74 & 4.49 & $53.88 \%(\downarrow)$ \\
\hline $\begin{array}{l}\text { Maximum bending moment of bridge piles } /\left(M_{y, \max } /\right. \\
\mathrm{kN} \cdot \mathrm{m})\end{array}$ & 422.3 & 334.8 & $20.72 \%(\downarrow)$ \\
\hline Maximum shear force of bridge piles $/\left(Q_{x, \max } / \mathrm{kN}\right)$ & 141.3 & 118.6 & $16.07 \%(\downarrow)$ \\
\hline
\end{tabular}

\section{Conclusions}

Based on the engineering background of the large-diameter shield construction of a subway tunnel sidecrossing the bridge pile foundations, the effects of shield construction passing by the overpass on bridge piers and pile foundations in the lower part of the overpass were analyzed by using numerical method. The main conclusions are made as follows:

(1) By referring to transverse surface subsidence curve calculated by Peck's formula, the reliability of the numerical model was verified. The results show that horizontal surface subsidence curve obtained by using the 3D numerical model for shield construction established in this study well coincides with that obtained by using Peck's formula, indicating that the numerical model is reliable to some extent.

(2) Due to different distances from the tunnel, changes of vertical displacement of the two bridge piers during shield construction have certain differences. Since QD-1 is closer to the tunnel and its pile foundation is located within the upheaval range at the bottom of the tunnel, the bridge pier produces upheaving deformation when the excavation face passes by and upheaval further increases after the shield tail departs the pile foundation. The relative subsidence of the two bridge piers has obvious stages, suggesting that the longitudinal influence range of shield construction mainly concentrate between excavation lengths of $L=20 \mathrm{~m}$ and $L=40 \mathrm{~m}$.

(3) Compared with uneven vertical subsidence, horizontal displacement of the bridge piers along the overpass caused by the shield machine side-crossing the overpass is more significant. After the construction, the relative displacement of the two bridge piers along the overpass is $19.87 \mathrm{~mm}$. Although it is smaller than the control value $(29.60 \mathrm{~mm})$ in the specifications, it almost reaches the early warning value $(20.72 \mathrm{~mm})$ for construction.

(4) In view of relative position of the shield machine and bridge piles, transverse deformation of bridge piles caused by shield construction is S-shaped. Flexural deflection of pile foundation away from the tunnel is shown at the tunnel axis, while deviation to the tunnel is found at the top and end of the pile. The position with the maximum transverse deformation of the pile foundation is slightly above the tunnel axis. The closer it is to the tunnel, the larger the deformation of the pile foundation is. The analysis on deformation of the pile 
foundations on the same side demonstrates that deformation of the pile foundations in the rear row significantly reduces because of isolation effect of those in the front row.

(5) Deformation characteristics of additional internal force of the pile foundations in the transverse direction caused by shield construction are similar to the additional deformation in the direction. However, the maximum shear force and bending moment have small difference in position. The position of the maximum bending moment is basically consistent with that showing the maximum transverse deformation, slightly above the tunnel axis, while the position of the maximum shear force is slightly below the tunnel axis.

(6) Based on the established numerical model, the proposed measures for protecting pile foundations at site were verified. The calculation results illustrate that the measure of reinforcing strata can effectively control deformation of bridge piers and pile foundations during shield construction. After reinforcing strata, relative horizontal displacement of bridge piers along the overpass is only $6.35 \mathrm{~mm}$ and the maximum horizontal displacement on the top of the piles is only $0.94 \mathrm{~mm}$, which are much lower than the control values in the specifications and early warning values for construction.

\section{Declarations}

\section{Acknowledgments}

This study is financially supported by the Scientific Research Projects of Hunan Provincial Department of Education (Grants No. 15C0256). The authors greatly appreciate the helpful comments and suggestions of the anonymous reviewers.

\section{References}

Attewell PB (1982) Predicting the dynamics of ground settlement and its derivatives caused by tunnelling in soil. Ground engineering, 15(8): 13-22.

Boldini D, Losacco N, Bertolin S, Amorosi A (2018) Finite element modelling of tunnelling-induced displacements on framed structures. Tunnelling and Underground Space Technology, 80: 222-231.

Chen WZ, Wu GJ, Jia SP (2010) Application of ABAQUS in Tunnelling and Underground engineering, China Water Power Press, Beijing (in Chinese).

Cheng H, Chen J, Chen G (2019) Analysis of ground surface settlement induced by a large EPB shield tunnelling: a case study in Beijing, China. Environmental Earth Sciences, 78(20): 1-18.

Kaalberg FJ, Teunissen EAH, Van TAF, Bosch JW (2005) Dutch research on the impact of shield tunnelling on pile foundations. In Proceedings of the 5th international symposium on geotechnical aspects of underground construction in soft ground: 123-131.

Li P, Lu Y, Lai J, Liu H, Wang K (2020) A comparative study of protective schemes for shield tunneling adjacent to pile groups. Advances in Civil Engineering, 2020: 1-16. 
Liu C, Zhang Z, Regueiro RA (2014) Pile and pile group response to tunnelling using a large diameter slurry shield-Case study in Shanghai. Computers and Geotechnics, 59: 21-43.

Lv J, Li X, Li Z, Fu H (2020) Numerical simulations of construction of shield tunnel with small clearance to adjacent tunnel without and with isolation pile reinforcement. KSCE Journal of Civil Engineering, 24(1): 295309.

Mashimo H, Ishimura T (2003) Evaluation of the load on shield tunnel lining in gravel. Tunnelling and underground space technology, 18(2-3): 233-241.

Nematollahi M, Dias D (2019) Three-dimensional numerical simulation of pile-twin tunnels interaction-Case of the Shiraz subway line. Tunnelling and Underground Space Technology, 86: 75-88.

Peck RB (1969) Deep excavations and tunneling in soft ground. Proc. 7th ICSMFE, 1969: 225-290.

Sirivachiraporn A, Phienwej N (2012) Ground movements in EPB shield tunneling of Bangkok subway project and impacts on adjacent buildings. Tunnelling and underground space technology, 30: 10-24.

Teparaksa W, Tangpraprutgul T, Boonsong C, Boonard J (2006) Ground and bridge displacement due to epb shield tunnel bored underneath bridge pile foundation. In Proceedings of the International Symposium on Underground Excavation and Tunnelling: 299-307.

Xu Q, Zhu H, Ma X, Ma Z, Li X, Tang Z, Zhuo K (2015) A case history of shield tunnel crossing through group pile foundation of a road bridge with pile underpinning technologies in Shanghai. Tunnelling and Underground Space Technology, 45: 20-33.

Xu X, Li Z, Fang Q, Zheng H (2020) Challenges and countermeasures for using pile-beam-arch approach to enlarge large-diameter shield tunnel to subway station. Tunnelling and Underground Space Technology, 98: 103326.

Zhang M, Li S, Li P (2020) Numerical analysis of ground displacement and segmental stress and influence of yaw excavation loadings for a curved shield tunnel. Computers and Geotechnics, 118: 103325.

\section{Figures}




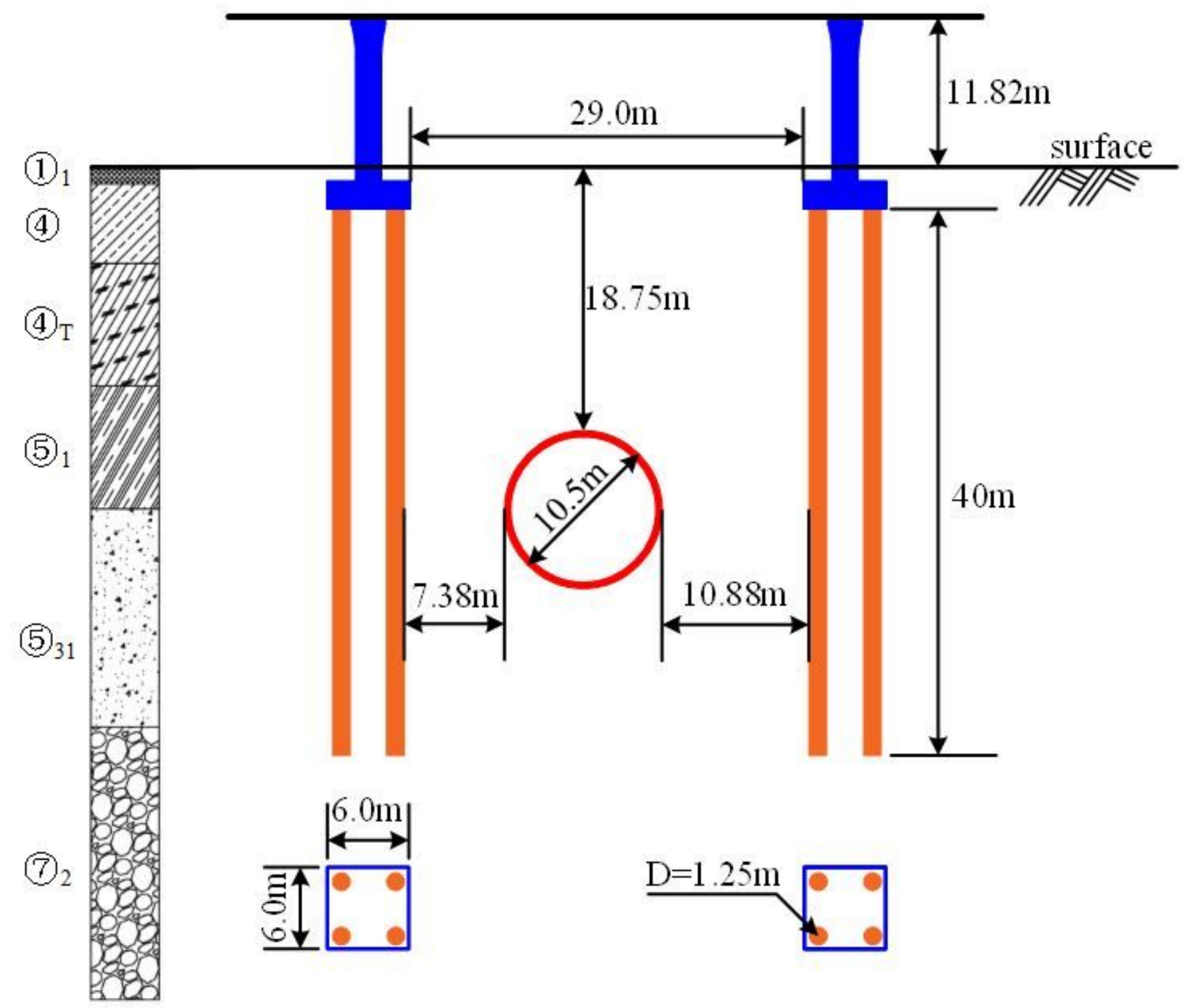

Figure 1

Transverse section of shield construction side-crossing pile foundations 


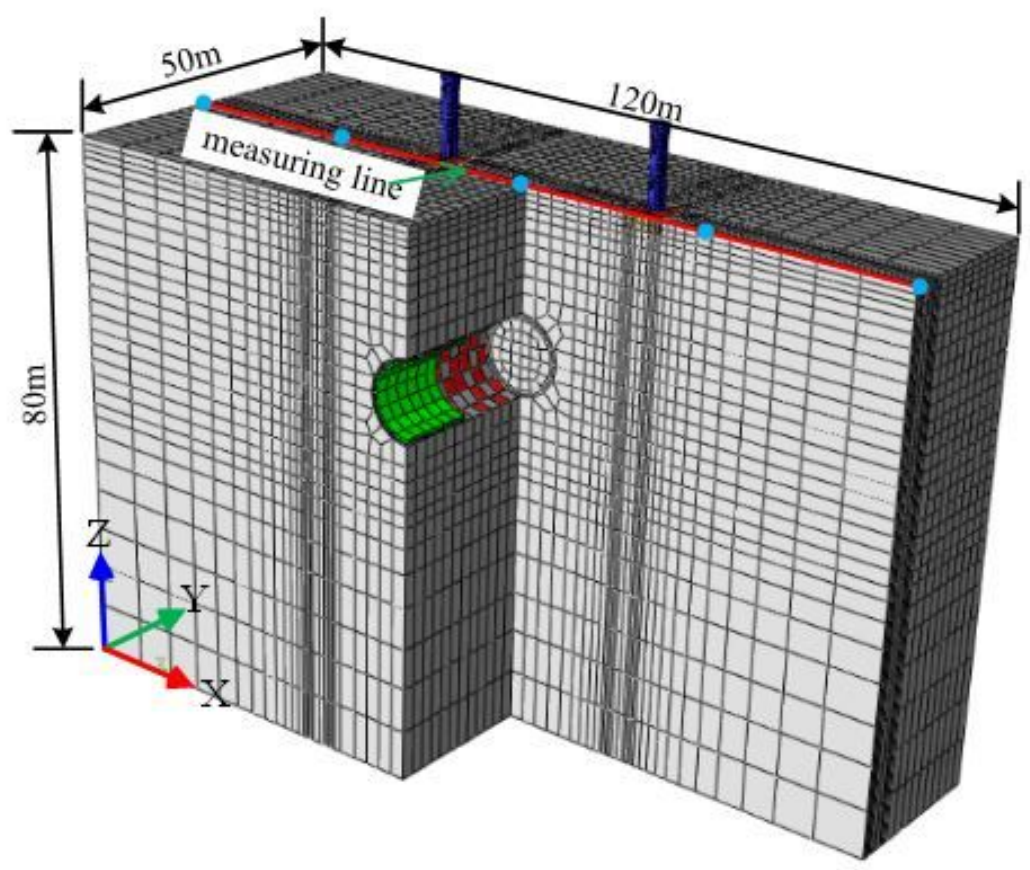

(a) Overall model grid

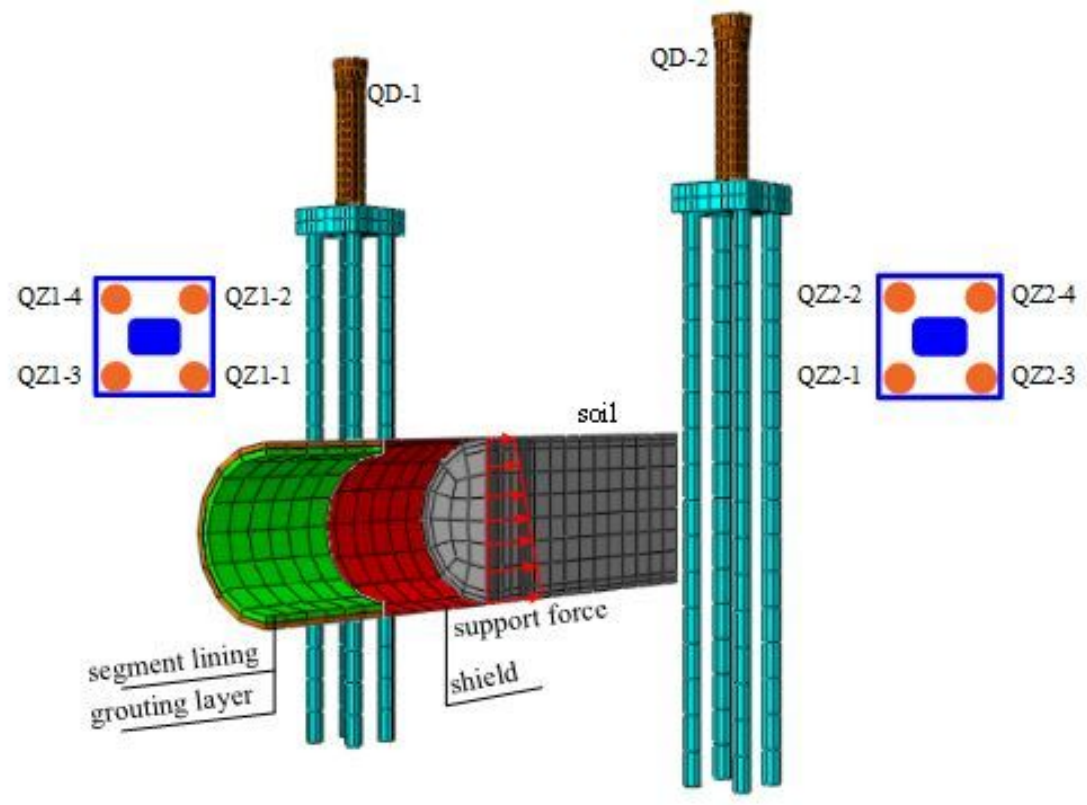

(b) Local details of the model

Figure 2

3D numerical model 


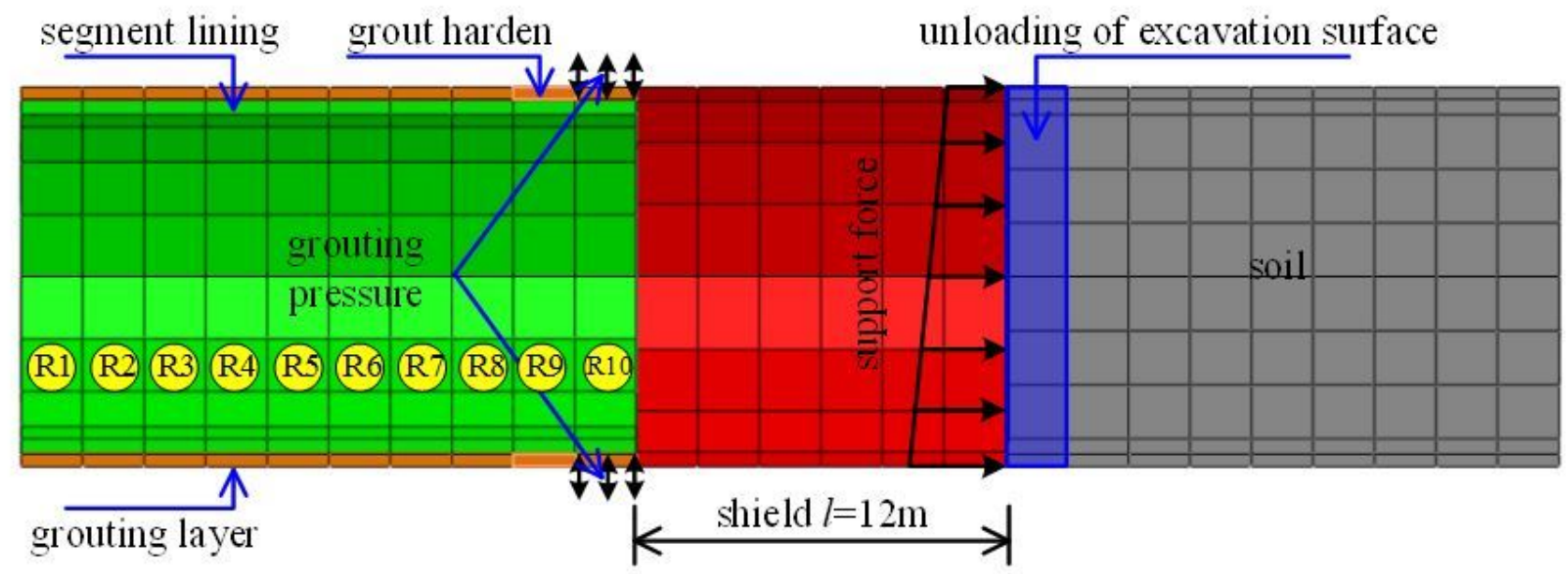

Figure 3

Simulation of shield construction

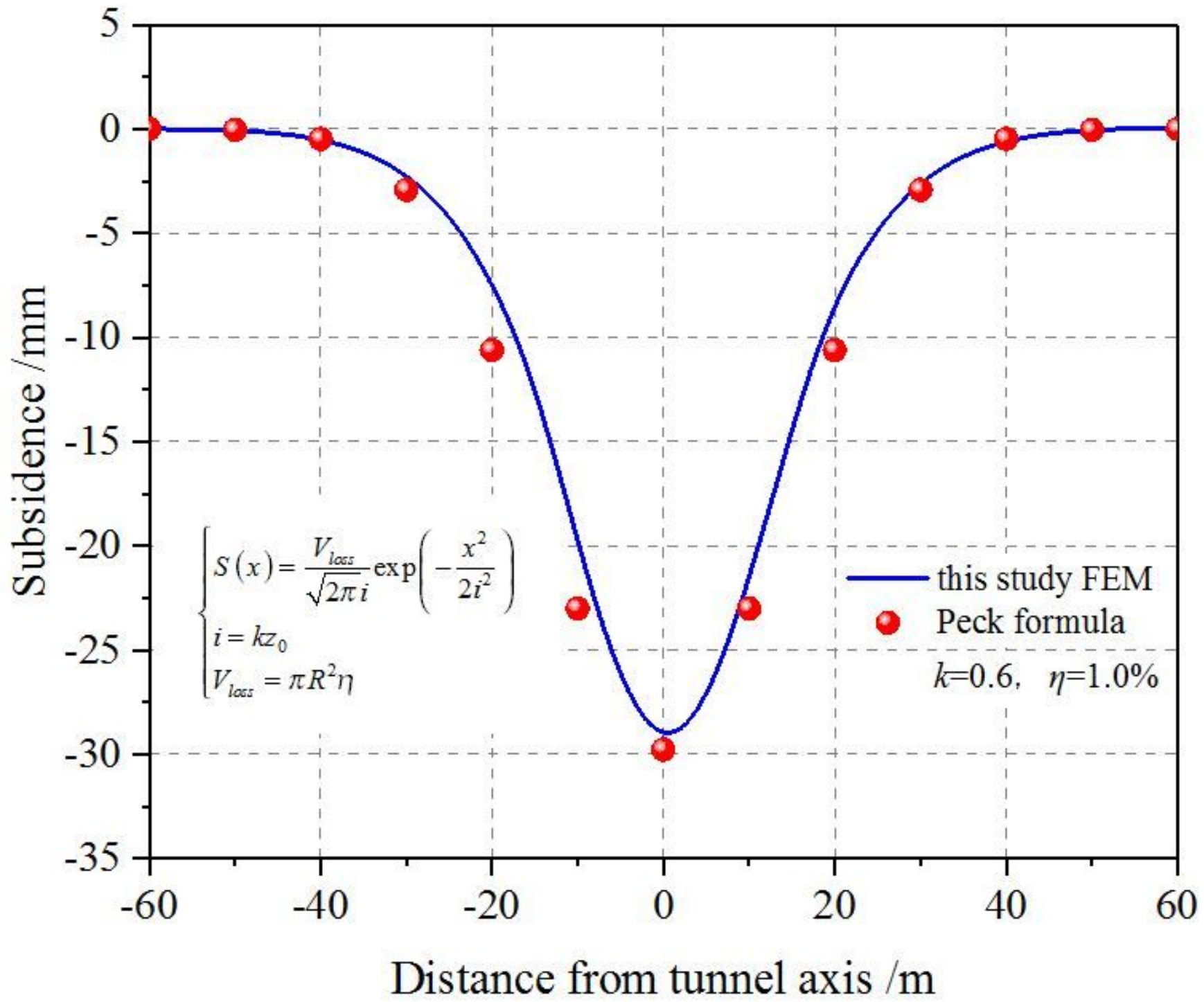

Figure 4 
Transverse surface subsidence curves

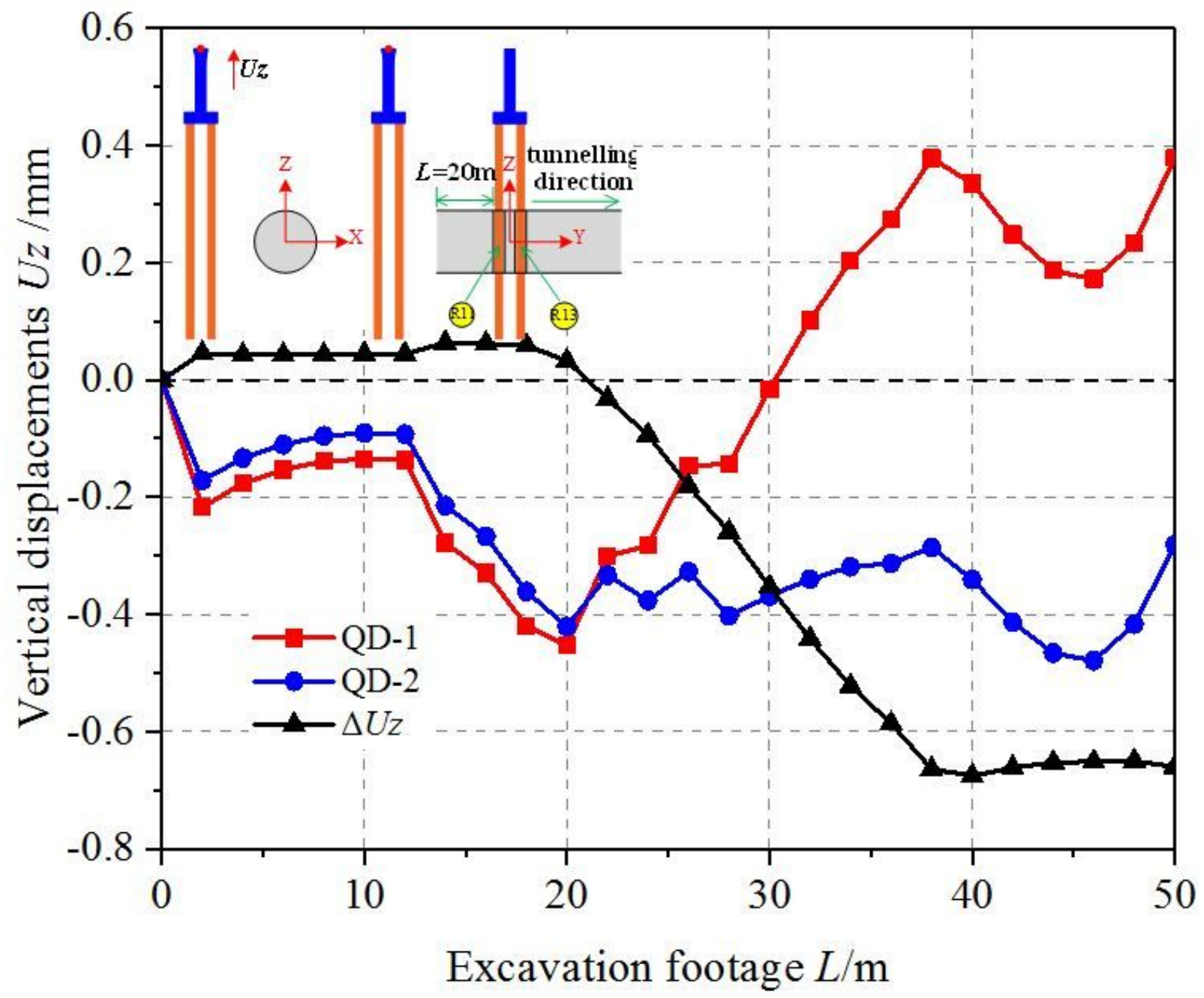

Figure 5

Change curve of vertical displacement of bridge piers 


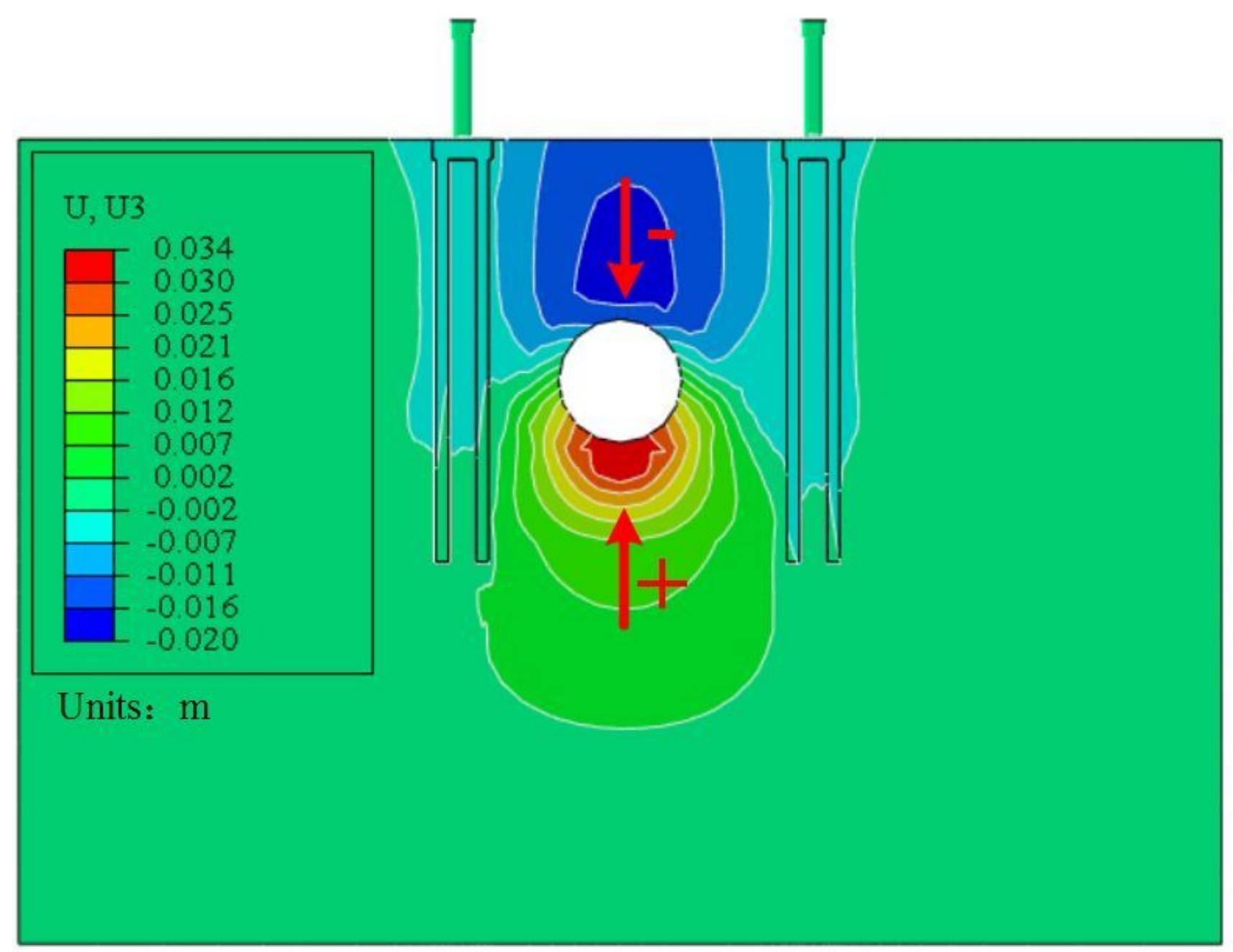

Figure 6

Cloud picture of vertical deformation of the overpass and soil under $L=30 \mathrm{~m}$ 


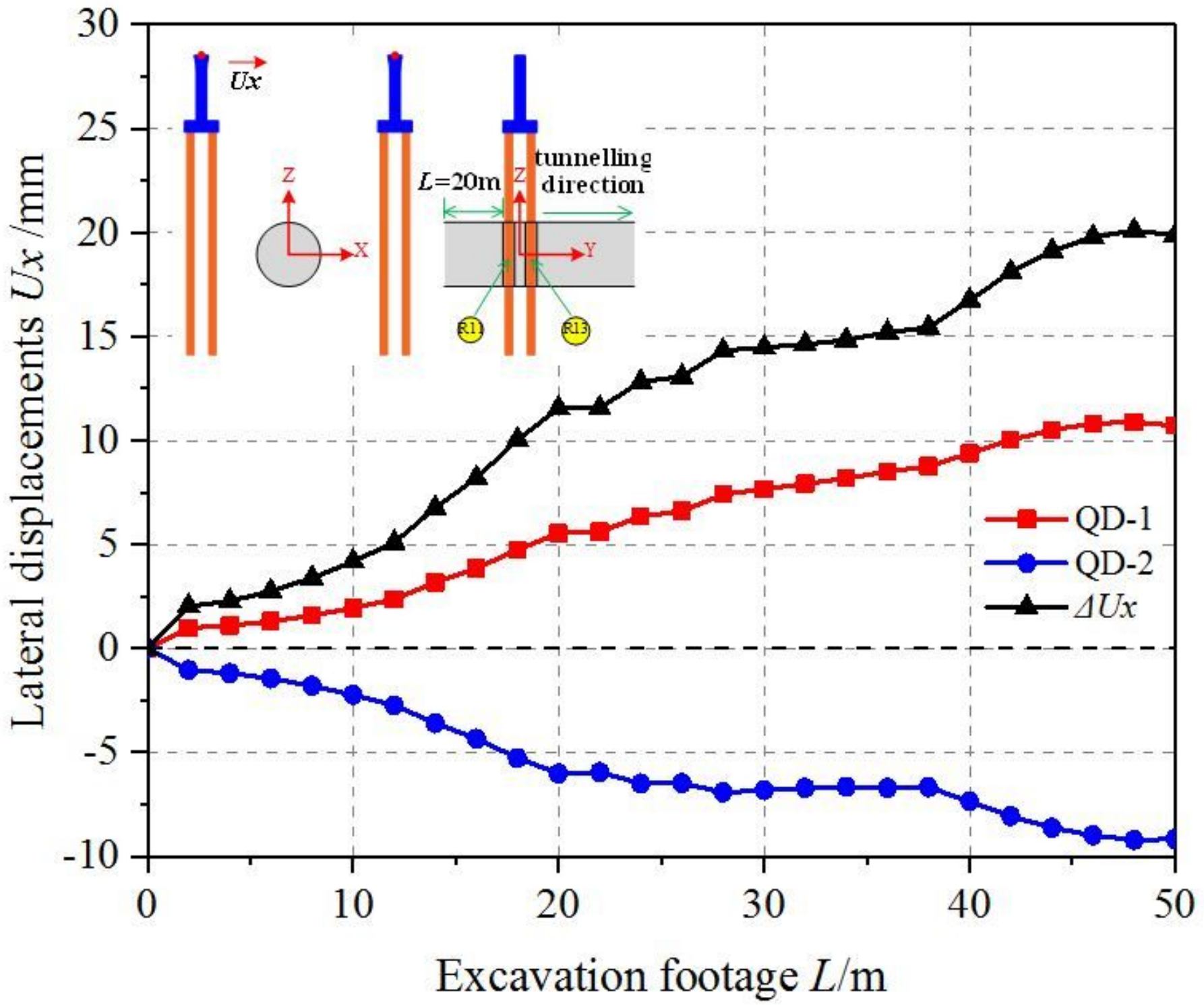

Figure 7

Change curve of horizontal displacement of the bridge piers along the overpass 


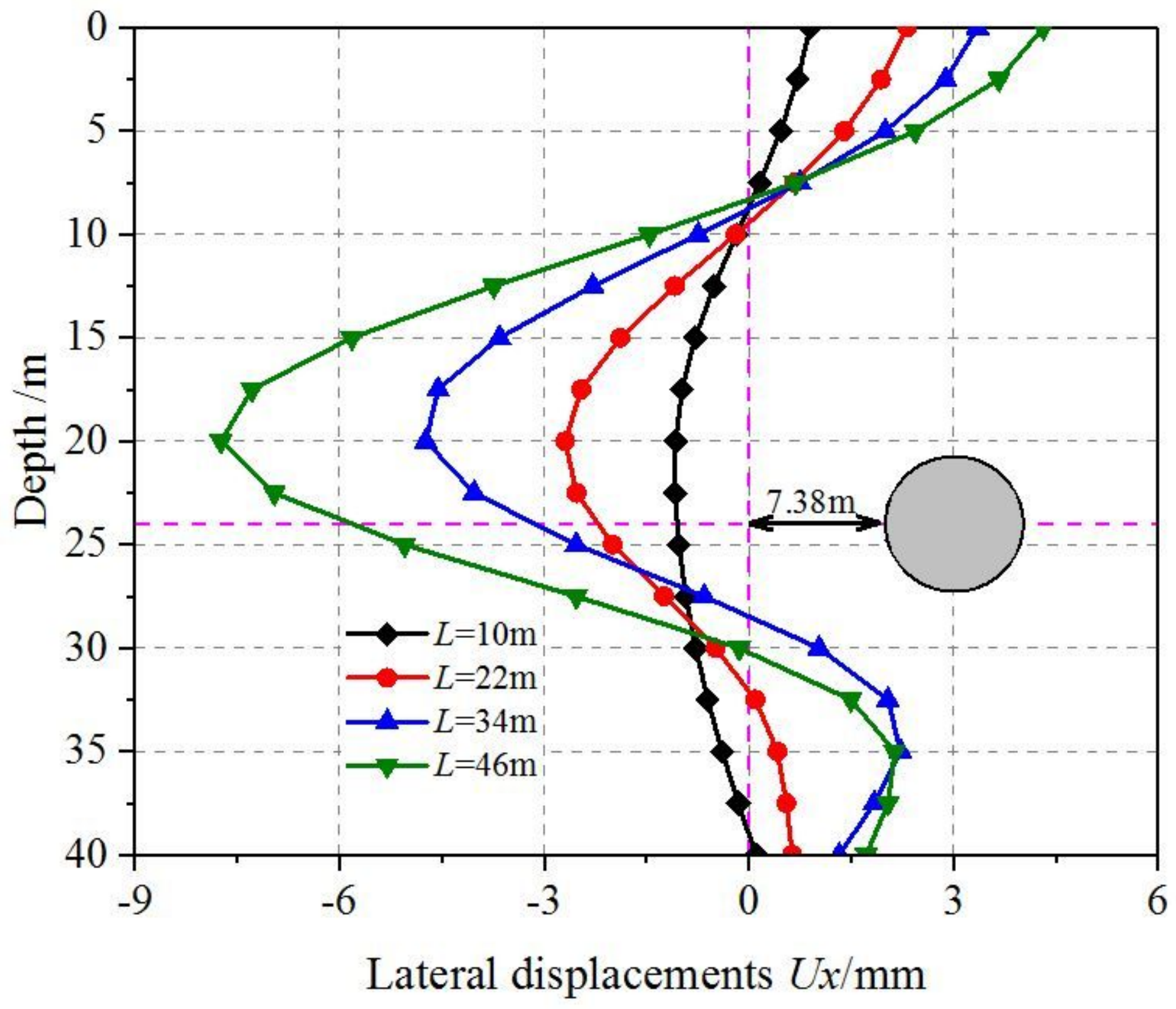

Figure 8

Transverse deformation of QZ1-1 under different working conditions 


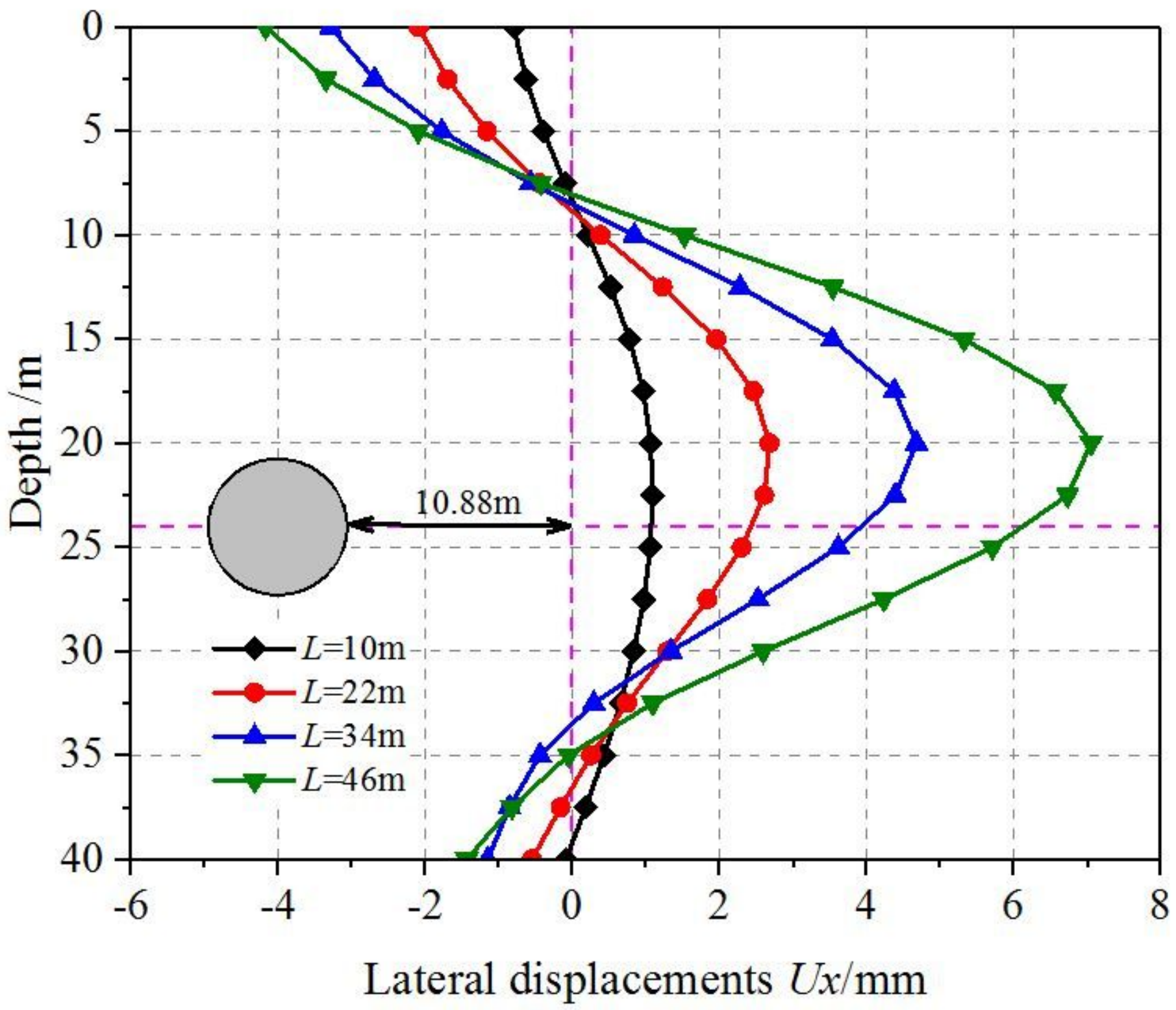

Figure 9

Transverse deformation of QZ2-1 under different working conditions 


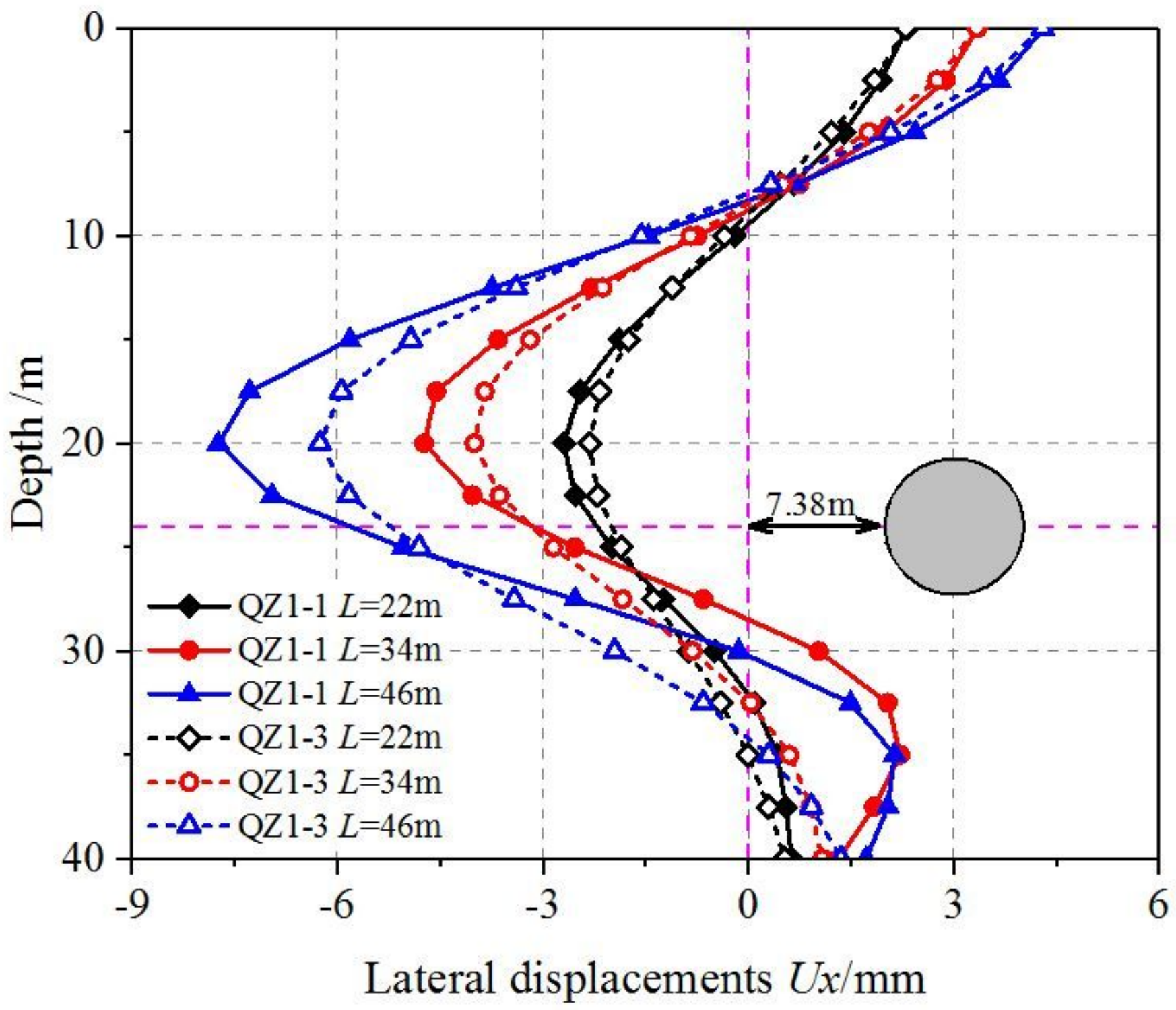

Figure 10

Transverse deformations of QZ1-1 and QZ1-3 under different working conditions 

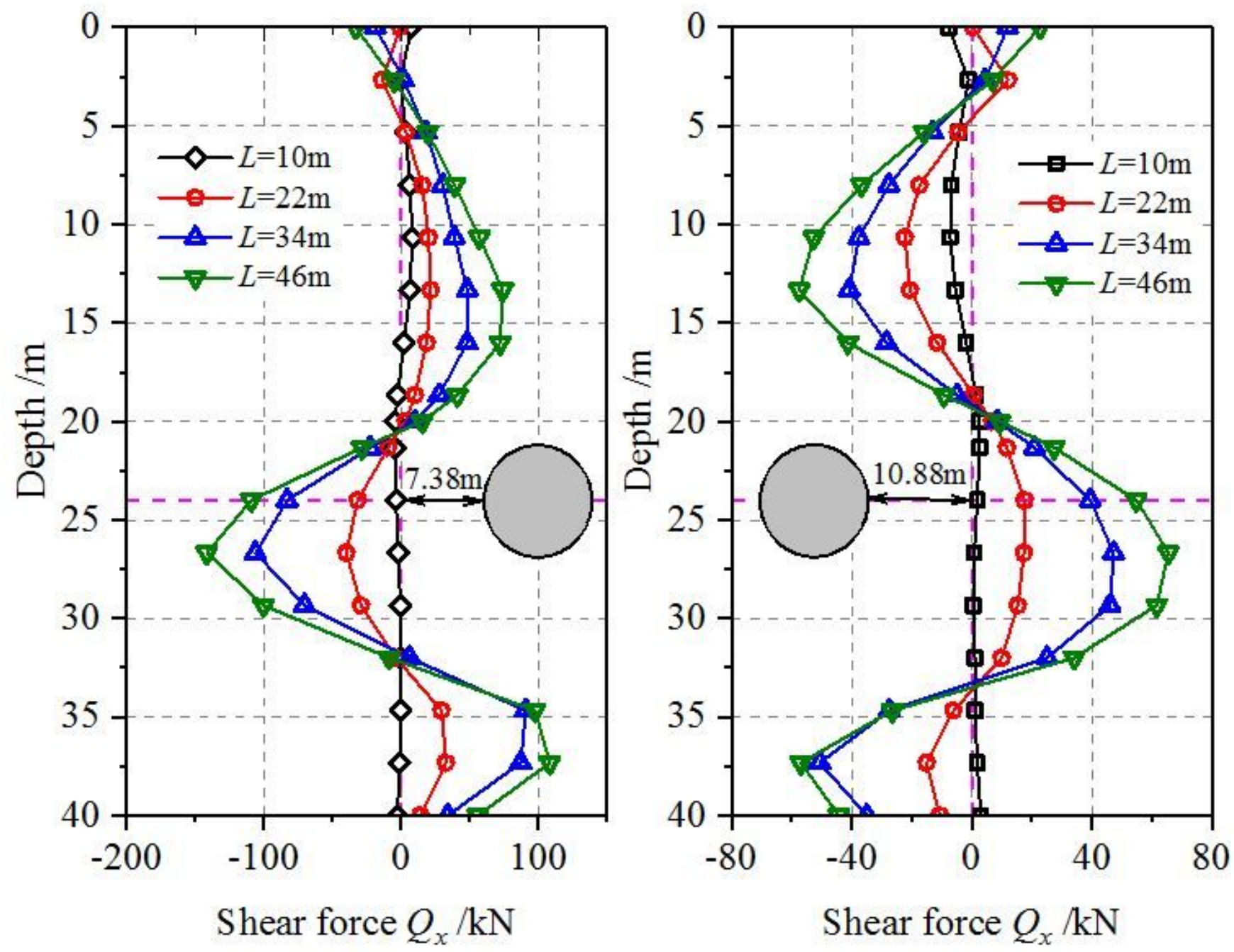

Figure 11

Shear forces of QZ1-1 and QZ2-1 under different working conditions 

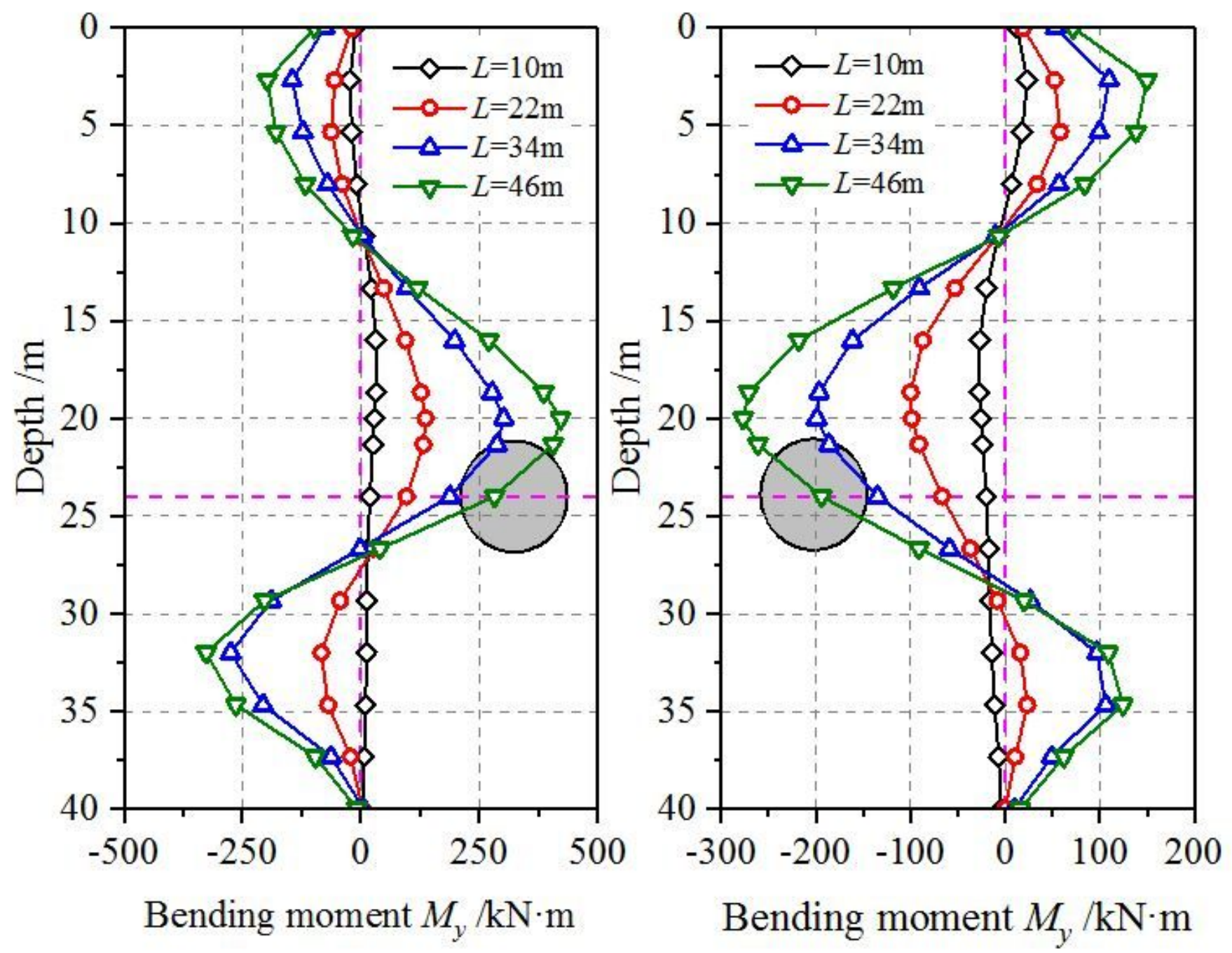

Figure 12

Bending moments of QZ1-1 and QZ2-1 under different working conditions 


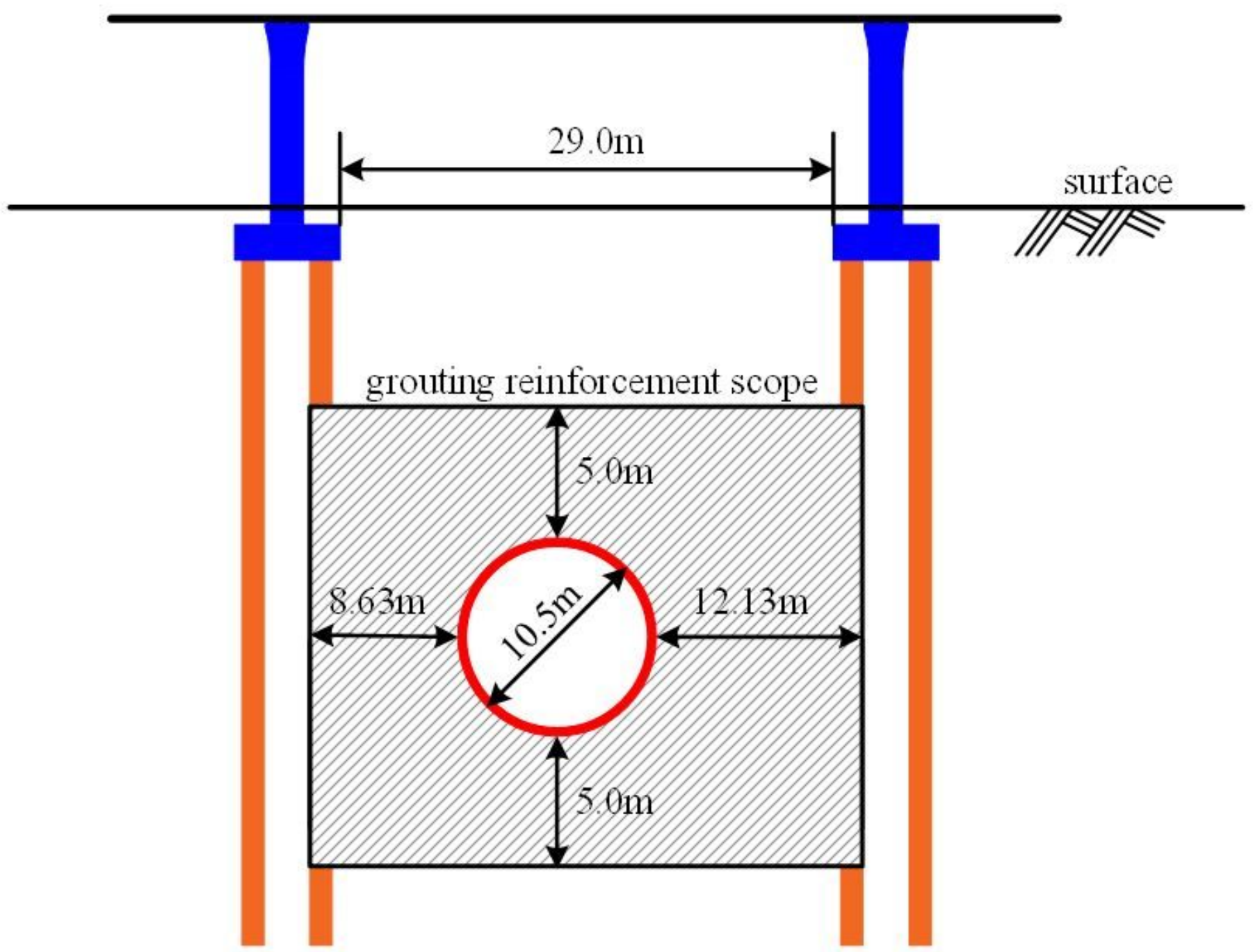

Figure 13

Transverse section with strata reinforced by grouting 